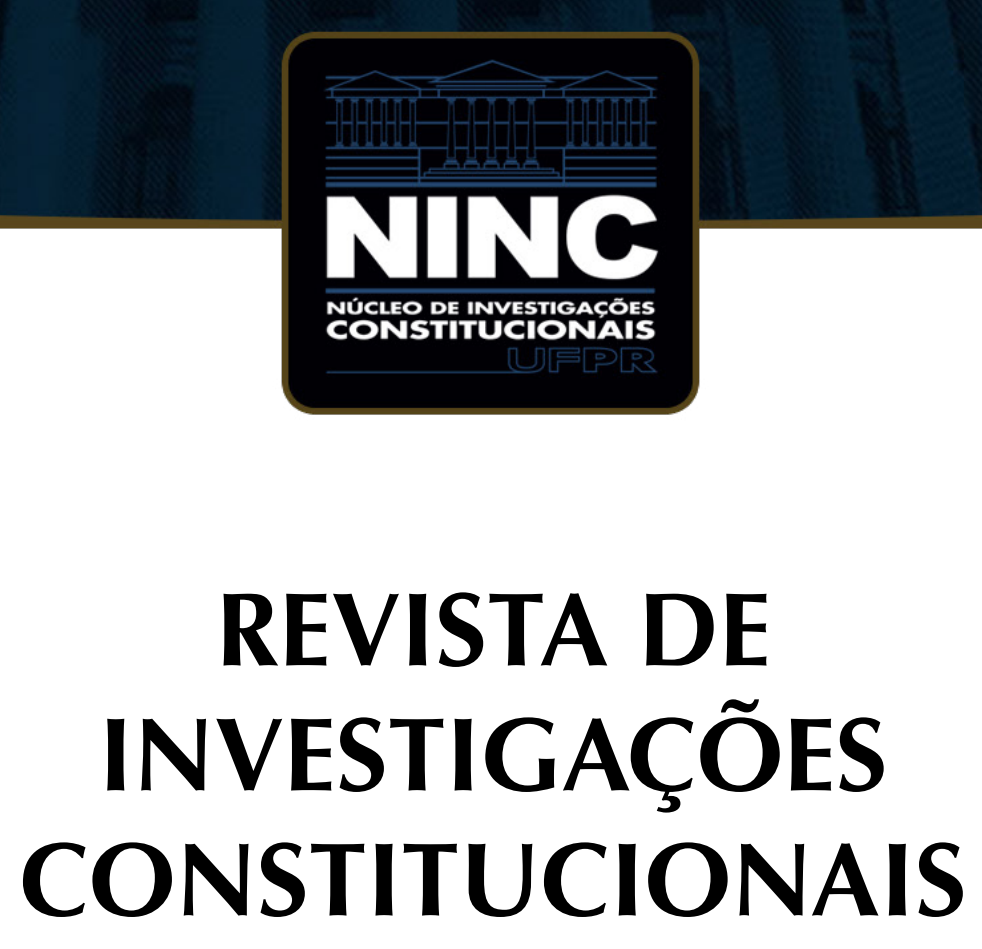

vol. 4 | n. 1 | janeiro/abril 2017 | ISSN 2359-5639 | Periodicidade quadrimestral Curitiba | Núcleo de Investigações Constitucionais da UFPR | www.ninc.com.br 


\title{
Emenda constitucional 95/2016 e o teto dos gastos públicos: Brasil de volta ao estado de exceção econômico e ao capitalismo do desastre
}

\section{Constitutional Amendment 95/2016 and the public spending ceiling: Brazil back to the state of economic exception and disaster capitalism}

\author{
CYNARA MONTEIRO MARIANO* \\ Universidade Federal do Ceará (Brasil)
} cynaramariano@gmail.com

Recebido/Received: 21.01.2017 / January 21th, 2017 Aprovado/Approved: 08.02.2017 / February 8th, 2017

Resumo

A proposta brasileira de implementação do teto para os gastos públicos federais, objeto das PEC's $241 / 55$, foi aprovada em 16 de dezembro de 2016, consolidando-se na Emenda Constitucional de número 95, que instituiu um novo regime fiscal para vigorar nos próximos 20 (vinte) anos, valendo, portanto, até 2036 . Referida proposta foi alvo de intensos protestos pela sociedade civil, sendo a causa de greves e ocupações estudantis que ocorreram nas escolas e universidades públicas de todo o país, o que não impediu, contudo, sua aprovação, eis que não se tratou de medida de iniciativa de um governo preocupado com sua popularidade e legitimidade. Além da ausência de diálogo com a sociedade civil, os protestos foram motivados pela oposição a um discurso oficial falacioso da necessidade de um novo regime fiscal, por meio da limitação de gastos e investimentos públicos, especialmente nos serviços de natureza social, como única medida capaz de retomar o crescimento da economia, que teria sucumbido diante de um suposto comportamento fiscal irresponsável do governo anterior. Pretendendo

\section{Abstract}

The Brazilian proposal for the implementation of the federal public spending ceiling, object of the Constitutional Amendment Proposals (PECs) 241/55, was approved on December 16, 2016, being consolidated into Constitutional Amendment number 95, which established a new fiscal regime to be in force over the next 20 (twenty) years, thus, being valid until 2036. Such proposal was the subject of intense protests by the civil society, being the cause of strikes and students' occupations that took place in public schools and universities throughout the country, which did not prevent, however, its approval, since it was not an initiative measure by a government concerned with its popularity and legitimacy. Besides the absence of dialogue with civil society, the protests were motivated by the opposition to an official fallacious discourse on the need for a new fiscal regime, by limiting public spending and investment, especially on services with a social nature, as the only measure capable of recovering the economic growth, which would have collapsed before an alleged irresponsible fiscal behavior of the previous government. Aiming to analyze that official discourse,

Como citar esse artigo/How to cite this article: MARIANO, Cynara Monteiro. Emenda constitucional 95/2016 e o teto dos gatos públicos: Brasil de volta ao estado de exceção econômico e ao capitalismo do desastre. Revista de Investigações Constitucionais, Curitiba, vol. 4, n. 1, p. 259-281, jan./abr. 2017. DOI:10.5380/rinc.v4i1.50289.

* Professora Adjunta da Faculdade de Direito da Universidade Federal do Ceará (Fortaleza-CE, Brasil). Pós-Doutora em Direito pela Universidade de Coimbra. Doutora em Direito Constitucional pela Universidade de Fortaleza (UNIFOR). Mestre em Direito Público pela UFC. Vice-Presidente do Instituto Latino Americano de Estudos sobre Direito, Política e Democracia (ILAEDPD) e Diretora Acadêmica do Instituto Cearense de Direito Administrativo (ICDA). Advogada. E-mail: cynaramariano@gmail.com. 
analisar esse discurso oficial e os impactos da novel EC $95 / 2016$, o presente artigo, utilizando-se de uma metodologia qualitativa e exploratória, debruçar-se-á sobre o conteúdo da Emenda e da mensagem das propostas de origem, para, ao final, concluir que a medida se trata de mais uma tentativa das forças do capital, nacional e supranacional, para manter o Brasil no seu permanente Estado de Exceção econômico, no qual se deseja manter, aliás, toda a América Latina.

Palavras-chave: teto dos gastos públicos; Emenda Cons titucional 95/2016; Estado de Exceção Econômico; neoliberalismo e colonialismo; capitalismo de desastre. and the impacts of the new Constitutional Amendment (CA) 95/2016, this article, by using a qualitative and exploratory methodology, shall focus on the content of the Amendment and the message of the original proposals, so that, at the end, one concludes that such measure is yet another attempt by the national and supranational capital powers, to keep Brazil in its permanent State of Economic Exception, in which some also desire to keep, in fact, all Latin America.

Keywords: public spending ceiling; Constitutional Amendment 95/2016; State of Economic Exception; neoliberalism and colonialism; disaster capitalism.

\section{SUMÁRIO}

1. Introdução; 2. Das premissas e falácias da necessidade do teto de gastos públicos; 3 . Considerações finais; 4. Referências.

\section{INTRODUÇÃO}

A Emenda Constitucional n. ${ }^{\circ}$ 95/2016 foi resultado das Propostas 241 e 55, que tramitaram, respectivamente, na Câmara dos Deputados e no Senado Federal, alcançando sua votação final, em segundo turno nesta última casa legislativa, no dia 16 de dezembro de 2016. A partir de então, foram inseridos no Ato das Disposições Constitucionais Transitórias (ADCT) vários dispositivos que implementaram um novo regime fiscal com um limite para os gastos do governo federal, que vigorará pelos próximos 20 (vinte) anos. Esse novo regime valerá, portanto, até 2036, sendo o teto fixado para 2017 correspondente ao orçamento disponível para os gastos de 2016, acrescido da inflação daquele ano. Para a educação e a saúde, o ano-base será este 2017, com início de aplicação em 2018. Qualquer mudança nas regras só poderá ser feita a partir do décimo ano de vigência do regime, e será limitada à alteração do índice de correção anual.

Desse modo, pelo recente art. 102 do ADCT, será fixado, para cada exercício, um limite individualizado para a despesa primária total (que corresponde ao montante da despesa total antes do pagamento dos juros da dívida) do Poder Executivo, do Poder Judiciário, do Poder Legislativo, do Tribunal de Contas da União, do Ministério Público da União e da Defensoria Pública da União, cabendo a cada um deles a responsabilidade pelo estabelecimento do seu limite. Aumentos reais do limite estão vedados, pois, de acordo com o $\S 3 .^{\circ}$, inciso II desse mesmo artigo 102, nos exercícios posteriores a 2017, o limite dos gastos corresponderá ao valor do limite referente ao exercício imediatamente anterior, corrigido pela variação do Índice de Preços ao Consumidor Aplicado - IPCA (e assim sucessivamente). Apenas aumentos nominais são possíveis, portanto. 
As regras do novo regime não permitem, assim, o crescimento das despesas totais e reais do governo acima da inflação, nem mesmo se a economia estiver bem, o que diferencia o caso brasileiro de outras experiências estrangeiras que adotaram o teto de gastos públicos. Somente será possível aumentar os investimentos em uma área desde que sejam feitos cortes em outras. As novas regras desconsideram portanto, as taxas de crescimento econômico, como também as demográficas pelos próximos 20 (vinte anos), o que (e aqui já antecipando a nossa crítica a respeito), poderá levar ao sucateamento das políticas sociais, especialmente nas áreas da saúde e educação, pondo em risco por completo a qualidade de vida da população brasileira.

Fixado o teto uma única vez, isso vinculará todos os fenômenos administrativos que ocorrerem nas várias unidades, órgãos e pessoas administrativas acima citadas, pelos próximos 20 (vinte) anos, o que, obviamente, impedirá os investimentos necessários à manutenção e expansão dos serviços públicos, incorporação de inovações tecnológicas, aumentos de remuneração, contratação de pessoal, reestruturação de carreiras, o que se faz necessário em virtude do crescimento demográfico, e sobretudo em razão dos objetivos e fundamentos constitucionais, que direcionam um projeto constituinte de um Estado de Bem Estar Social. O novo regime fiscal suspende, por consequência, o projeto constituinte de 1988, e retira dos próximos governantes a autonomia sobre o orçamento, salvo se houver, no futuro, em uma nova gestão, outra proposta de emenda constitucional em sentido contrário. Retira também do cidadão brasileiro o direito de escolher, a cada eleição, o programa de governo traduzido no orçamento e, com isso, decidir pelas políticas públicas prioritárias para o desenvolvimento econômico ${ }^{12}$.

\footnotetext{
1 Com isso, o teto dos gastos públicos impede o gozo de um direito fundamental universal, pois não há como se promover o desenvolvimento econômico sem o acesso do povo às políticas públicas mais básica, como a saúde e a educação. Vários documentos da Organização das Nações Unidas consagram o direito ao desenvolvimento como um direito fundamental dos povos: o art. 55 da Carta da ONU, o Pacto Internacional de Direitos Econômicos, Sociais e Culturais (16 de dezembro de 1996), a Declaração sobre o Progresso e o Desenvolvimento no Domínio Social (11 de dezembro de 1969), a Declaração sobre o Direito ao Desenvolvimento (aprovada pela Assembleia Geral em 1986) e o Programa de Ação aprovado em Viena em 1993, na Conferência das Nações Unidas sobre Direitos Humanos, em que se proclamou que o direito ao desenvolvimento é "um direito humano universal e inalienável e um a parte integrante dos direitos fundamentais".

2 Cumpre aqui insistir na ressalva quanto a uma eventual compreensão do desenvolvimento econômico como ideia atrelada ao crescimento econômico, traduzido como crescimento da produção ou do Produto Interno Bruto (PIB). Para tanto, valemo-nos também das bem sintetizadas observações de Avelãs Nunes, a incluírem o desenvolvimento integral do homem na perspectiva do desenvolvimento econômico: "em primeiro lugar, a ideia de que o desenvolvimento económico (sic) passa por caminhos que respeitem a dignidade do homem, o desenvolvimento integral da sua personalidade, a conquista do bem-estar material, mas também o desenvolvimento dos homens no plano da sua profissão, da cultura e do lazer. Amartya Sem lembra com justeza que o desenvolvimento é 'um processo de expansão das liberdades reais de que as pessoas desfrutam' e que 'a expansão da liberdade humana é tanto o principal fim como o principal meio do desenvolvimento'. Em segundo lugar, a ideia de que o desenvolvimento é condicionado por determinadas estruturas e implica, portanto, transformações mais ou menos profundas dessas estruturas (a estrutura da propriedade, a estrutura das relações de produção, as estruturas sociais, a própria estrutura do poder político). Em terceiro, a ideia de que, sem ignorar a necessidade do crescimento económico (sic) do PND, o desenvolvimento deve colocar-se, fundamentalmente, ao serviço das necessidades básicas das populações (alimentação, saúde, educação de
} 
Além da suspensão do projeto constituinte de 1988, o novo regime fiscal revela uma clara opção por uma antidemocracia econômica, inviabilizando a expansão e até mesmo a própria manutenção de políticas públicas para reservar dinheiro público e garantir o pagamento das obrigações assumidas pelo governo federal brasileiro perante os credores da dívida pública. Essa lógica pode ser observada pelo $\S 6 .^{\circ}$ desse mesmo artigo 102 do ADCT, que estabeleceu ficarem excluídos do teto: I - as transferências constitucionais relativas à: a) participação dos Estados e Municípios no produto da exploração de petróleo e gás natural; b) repartição das receitas tributárias; c) cotas estaduais e municipais da contribuição social do salário-educação; d) as despesas relativas aos serviços da polícia civil, polícia militar, bombeiros e demais serviços públicos do Distrito Federal; e) e a complementação das cotas do salário-educação do DF e Estados caso o número de alunos não atinja o limite necessário; II - os créditos extraordinários abertos para atender a para atender a despesas imprevisíveis e urgentes, como as decorrentes de guerra, comoção interna ou calamidade pública; III - despesas com a realização de eleições pela justiça eleitoral; IV - outras transferências obrigatórias derivadas de lei que sejam apuradas em função de receitas vinculadas; e V - despesas com aumento de capital de empresas estatais não dependentes.

Ou seja, os maiores problemas do novo regime fiscal residem nesse $\S 6 .^{\circ}$ do art. 102. Não foram excluídos do teto o pagamento de juros e amortizações da dívida pública, que podem se avolumar livremente. No Japão, essa falta de controle da dívida a fez triplicar a partir do terceiro ano de vigência do teto. Também não foram excluídos do teto, no Brasil, os percentuais obrigatórios de gastos com a saúde e educação. A Constituição, como se sabe, exige que os governos apliquem um percentual mínimo de sua receita em educação e saúde. A União federal é obrigada a aplicar na saúde ao menos o mesmo valor do ano anterior mais o percentual de variação do Produto Interno Bruto (PIB). Estados e Municípios precisam investir 12\% e 15\%, respectivamente. Na educação, a União federal deve gastar $18 \%$ do arrecadado, e Estados e Municípios 25\%. Sem essa exclusão do teto, o financiamento do Sistema Único de Saúde (SUS) nos Estados e Municípios será fortemente atingido, pois cerca de 2/3 das despesas do Ministério da Saúde são transferidas fundo a fundo para ações de atenção básica, média e alta complexidade, assistência farmacêutica, vigilância epidemiológica e sanitária, entre outras, a cargos dos entes federados.

O próprio Ministro da Fazenda do novo governo, Henrique Meirelles, confirmou em entrevista, que a chamada "desvinculação das despesas obrigatórias com saúde e

base, serviços de água e saneamento, transportes e habitação). O conceito de necessidades básicas implica a satisfação de necessidades imediatas, mas também de necessidades cuja satisfação é, nos dias de hoje, um pressuposto indispensável para que as pessoas possam efetivamente (sic) atingir níveis razoáveis de produtividade e desenvolver actividades (sic) produtivas suficientemente remuneradoras, o que significa a acentuação do carácter social destas necessidades (NUNES, António José Avelãs. Neoliberalismo \& Direitos Humanos. Rio de Janeiro: Renovar, 2003. p. 11-112). 
educação" é "parte fundamental e estrutural" do novo regime fiscal3. Não deveria ser preciso dizer que isso é inconstitucional, pois atenta contra a lógica principiológica da vedação ao retrocesso social, consubstanciada no plano do direito positivo, no rol das cláusulas pétreas constitucionais do $§ 4 .^{\circ}$ do art. 60.4

Exemplificativamente, tome-se o total dos R\$ 129,7 bilhões destinados ao orçamento da educação no ano de 2016. Desse valor, R\$ 51,6 bilhões são do piso constitucional de 18\%. Deste segundo valor, R\$ 50,5 bilhões são despesas obrigatórias e financeiras, como pagamento de salários de professores e aposentadorias. Com a desvinculação, portanto, a educação pode perder metade do seu orçamento, que é imprescindível para a própria manutenção. A expansão do serviço está vedada, pois implica em aumento de despesa real, a não ser que seja acompanhada de corte em outras áreas. Para uma outra ideia dos impactos do novo regime fiscal nas políticas sociais, é interessante recorrer também a um estudo do Departamento Intersindical de Estatísticas e Estudos socioeconômicos - DIEESE, que fez uma projeção do teto dos gastos aplicado como se estivesse em vigor nos anos de 2002 a $2015^{5}$. No caso da educação, com a nova regra, a redução seria de $47 \%$ no período. Já com relação às despesas de saúde, a redução seria de $27 \%$. Isso significa, em valores, que a perda na saúde, entre 2002 e 2015, teria sido de $\mathrm{R} \$ 295,9$ bilhões e, na educação, de $\mathrm{R} \$ \mathbf{6 7 3 , 6}$ bilhões, o que corresponderia a um montante total em torno de $\mathrm{R} \$ 969,5$ bilhões que, na lógica do novo regime fiscal já em vigor, seriam expropriados das políticas sociais para remunerar os investimentos dos donos da dívida pública brasileira. Já de acordo com um estudo do IPEA, divulgado no início do mês de outubro de 2016, somente o SUS perderá, com o novo regime fiscal, cerca de $\mathrm{R} \$ 743$ bilhões $^{6}$.

Outro problema, associado à liberdade para o crescimento da dívida pública, é a exclusão do teto das "despesas com aumento de capital de empresas estatais não dependentes". Neste ponto, para a compreensão do que isso significa, é necessário um cotejo entre as regras da novel EC 95/2016 com o PLS 204/2016, de autoria do atual Ministro das Relações Exteriores, José Serra, e com o PLP 181/2015 e PL 3337/2015. De acordo com análise da Auditoria Cidadã, o inciso V do $\S 6 .^{\circ}$ do novo art. 102 do ADCT, reserva recursos para o aumento de capital das empresas estatais não dependentes que, pelos citados projetos, vão legitimar um esquema financeiro de aprofundamento ainda maior do endividamento público, que está sendo apresentado à sociedade

3 Disponivel em: <http://economia.uol.com.br/noticias/redacao/2016/05/24/limites-com-educacao-e-saude-irao-ao-congresso-em-2-semanas-diz-meirelles.htm>.

4 Sobre a vedação ao retrocesso social aplicada aos serviços públicos e aos princípios do seu regime jurídico, conferir SCHIER, Adriana da Costa Ricardo. Serviço Público: garantia fundamental e cláusula de proibição de retrocesso social. Curitiba: Íthala, 2016. p. 209-235.

5 Disponível em: <http://www.dieese.org.br/notatecnica/2016/notaTec161novoRegimeFiscal.pdf>.

6 Disponível em: <http://www.ipea.gov.br/portal/images/stories/PDFs/nota_tecnica/160920_nt_28_disoc. pdf>. 
civil brasileira como a solução para resolver parte do endividamento dos Estados e Municípios7.

Por meio do PLS 204/2016, será legalizado, segundo a análise acima citada, um esquema financeiro que concede garantias públicas a essas empresas estatais não dependentes, que emitirão debêntures subordinadas sob o pretexto de cessão de direitos creditórios que não saem do lugar. Essas empresas serão constituídas na forma de sociedades de propósito específico, que não constituem um novo tipo societário, mas apenas uma previsão do Código Civil brasileiro de 2002 (art. 981, parágrafo único) de que uma sociedade pode ser constituída para finalidades específicas e com duração determinada. No caso da estatal não dependente, criada de acordo com o PLS 204, essas pessoas jurídicas não se submeterão a controle finalístico nem de contas (o que seria uma "novidade" no Direito administrativo)8, e serão constituídas com o propósito específico de realizar atividades financeiras, no caso em especial, para comprar créditos podres, prescritos etc., inscritos ou não em dívida ativa dos Estados e Municípios, com a outorga de garantias públicas federais, por meio da emissão de debêntures subordinadas, o que aprofundará ainda mais o endividamento da União Federal.

As debêntures serão vendidas a investidores privilegiados e não em hasta pública, porque são subordinadas, e esses investidores vão desembolsar um valor muito menor do que os juros que vão receber, pois pagarão um valor de $12,5 \%$ de face e receberão juros de até $23 \%$. Isso significa que a empresa estatal não dependente emite as debêntures e as vende a investidores privilegiados com deságio de até $60 \%$, que poderá ser pago parceladamente em 4 (quatro) vezes anuais, e paga juros de mais de $20 \%$. Assim, já no primeiro ano, quando paga a primeira parcela e recebe a remuneração em juros estratosféricos, o investidor já retira o seu investimento, e a estatal começa a acumular prejuízos. A estatal ainda arcará com os custos financeiros de consultorias, remuneração de administradores etc, onerando ainda mais o Estado. Os valores para arcar com esse rombo resultarão justamente das regras do novo regime fiscal que, ao promoverem o corte nos gastos sociais, reservam dinheiro para o pagamento desse desfalque. Ao acrescentar o art. 102 ao ADCT, a novel EC 95/2016 estabelece, no inciso $V$ do seu $\S 6 . .^{\circ}$, que "despesas com aumento de capital de empresas estatais não dependentes" ficam excluídas do teto, o que permite que esses recursos que estão sendo reservados sejam utilizados para aumento de capital dessas empresas para encobrir os

\footnotetext{
7 Disponível em: <http://www.auditoriacidada.org.br/blog/2016/09/08/9491>.

8 Lembrando que dentre os princípios da Administração pública indireta está o da especialidade e o do controle finalístico. Entidades da Administração pública indireta, ainda que de personalidade jurídica de direito privado, como o são essas estatais não dependentes, têm que ser criadas com finalidades específicas, claras, e em um mecanismo de intervenção indireta (ou direta para alguns) do Estado no domínio econômico, ou seja com a finalidade do interesse público. E por isso mesmo, sujeitam-se ao controle quanto às suas finalidades. Nenhum desses elementos está presente nesse PLS 204/2016.
} 
prejuízos. Essa, portanto, seria a razão da exclusão de tais despesas do teto de gastos, aparentemente sem sentido.

Ainda segundo estudo da Auditoria Cidadã, essa operação legaliza uma operação fraudulenta muito frequente nas privatizações que ocorreram no país, como no caso do Banestado, que resultou em um passivo que foi contabilizado na dívida pública do Estado do Paraná, que passou de milhões a bilhões após a privatização do banco estatal. Mesmo esquema financeiro que teria levado a Grécia a ruínas. Essa prática constitui, em essência, um grande esquema de transferência direta de receita do Estado para credores rentistas, e já foi vedada pelo Tribunal de Contas da União, como se pode ver pelo Relatório TC 016.585/2009-0, que a considerou uma antecipação de receita e, portanto, uma operação de crédito, assim definida no art. 29, incisos III e IV da Lei de Responsabilidade Fiscal. Isto é, uma mesma operação de crédito que resultou supostamente no afastamento presidencial de Dilma Rousseff, agora é legalizada pelo PLS 204/2016 e com o objetivo de aprofundar o endividamento público.

Importa explicitar que a Auditoria Cidadã, autora do estudo acima citado, está habilitada como entidade amiga da corte na ADPF 59/2004, proposta pelo Conselho Federal da Ordem dos Advogados do Brasil para obrigar, com base no art. 26 do ADCT, a auditoria da dívida pública brasileira ("no prazo de um ano a contar da promulgação da Constituição, o Congresso Nacional promoverá, através de Comissão mista, exame analítico e pericial dos atos e fatos geradores do endividamento externo brasileiro"). Referida ação direta está atualmente sob a relatoria do Ministro Luís Roberto Barroso, ainda sem previsão de julgamento. Interessante destacar, ainda sobre o assunto, que antes dessa ação direta, tentou-se apurar a origem da dívida pública brasileira por meio de uma Comissão Parlamentar de Inquérito - a CPI da dívida - de 2009, a qual restou frustrada porque o Banco Central se negou a fornecer as informações sobre os credores e as operações de endividamento alegando o dever de resguardar o sigilo bancário.

Nesse contexto, é nosso dever fazer a ressalva de que a imunidade da dívida pública ao controle de sua gestão não pode ser reputada como originalidade da atual Emenda Constitucional 95/2016. Mesmo que essa imunidade tenha sido herdada com o aprofundamento do Estado neoliberal brasileiro nos governos de Fernando Collor e Fernando Henrique Cardoso, ela também persistiu no "reformismo fraco" de Luís Inácio Lula da Silva. A feliz expressão de André Singer sintetiza bem a característica do governo lulista em promover, nos marcos da ordem burguesa neoliberal, um projeto de redistribuição de renda e combate à pobreza extrema sem confronto com o capital. 9 As virtudes políticas indiscutíveis do lulismo representaram, neste aspecto, ao mesmo tempo, os seus próprios limites ou os limites de um pós-neoliberalismo, pois revelaram

9 SINGER, André. Os sentidos do lulismo: Reforma gradual e pacto conservador. São Paulo: Companhia das Letras, 2012. 
uma incapacidade em promover investimentos sociais de profundidade nos serviços públicos, dada a submissão a um pacto conservador da governabilidade que exigia a manutenção e preservação da forma política do Estado neoliberal no Brasil. Disso resultou a incapacidade política dos governos pós-neoliberais de Lula e Dilma em romperem com o ciclo do pagamento de juros e amortização da dívida publica, subordinada aos interesses do capital financeiro, e com isso o projeto constituinte de 1988 do Estado de Bem Estar Social encontrou seu limite no sistema da divida pública, que exerce hoje um constrangimento sobre a Constituição e sobre os serviços públicos. A novel EC 95/2016 é uma tradução e um aprofundamento, portanto, desse sistema da dívida.

O novo art. 103 do ADCT ainda prevê que, no caso de descumprimento do limite de gastos, será aplicado ao poder ou órgão, no exercício financeiro seguinte, vedações quanto: a) à concessão de vantagem, aumento ou reajuste de remuneração, inclusive a titulo da revisão geral anual do inciso X do art. 37 da CF/88, exceto os derivados de sentença judicial ou de determinação legal anterior ao novo regime fiscal; b) à criação de cargo, emprego ou função que implique em aumento de despesa; c) à alteração de estrutura de carreira que implique em aumento de despesa; d) à admissão ou à contratação de pessoal, ressalvadas as reposições de cargos de chefia e de direção que não acarretem aumento de despesa e aquelas decorrentes de vacâncias de cargos efetivos; e e) à realização de concursos públicos. Ainda adicionalmente, ficará vedada a concessão de isenções fiscais.

O também novo art. 105 do ADCT, em contrariedade frontal com o princípio constitucional da inafastabilidade da jurisdição (art. 5. ${ }^{\circ}, \mathrm{XXXV}$ ), que também constitui cláusula pétrea, estabelece uma vedação à alegação de quaisquer controvérsias jurídicas decorrentes do novo regime fiscal, dispondo que "as vedações introduzidas pelo novo regime fiscal não constituirão obrigação de pagamento futuro pela União ou direitos de outrem sobre o erário".

Apesar das inconstitucionalidades patentes, o Supremo Tribunal Federal, ao apreciar o pedido de liminar no MS 34.448-MC/DF, que objetivava a suspensão da tramitação da antiga PEC 241, infelizmente negou a tutela cautelar, mas os fundamentos da decisão resumiram-se à negativa de lesão à separação dos poderes, à garantia do voto, secreto, direto, universal e periódico e ao direito de acesso ao Judiciário para fins de preservação da estrutura remuneratória dos servidores públicos. O STF não analisou ainda o mérito da proposta. Todavia, é possível antever, diante da última decisão tomada pela Corte que praticamente suprimiu o direito de greve do servidor público ${ }^{10}$,

10 Referimo-nos ao julgamento do Recurso Extraordinário 693456, aos 27 de outubro de 2016, com repercussão geral reconhecida, que discutiu a constitucionalidade do desconto dos dias parados em razão de greve do servidor público. Por 6 votos a 4, o Pleno do STF decidiu que a administração pública deve fazer o corte do ponto dos grevistas, mas admitiu a possibilidade de compensação dos dias parados mediante acordo. Também foi decidido que o desconto não poderá ser feito caso o movimento grevista tenha sido motivado por conduta ilícita do próprio Poder Público. Ao final do julgamento foi aprovada tese de repercussão geral com a seguinte 
às vésperas da deflagração de uma greve geral de resistência à PEC 241, que provavelmente o tribunal confirmará a constitucionalidade da proposta em sua substância, haja vista que a Corte tem se comportado cada vez mais como guardiã jurídica do novo governo, e não mais como guardiã da Constituição, como essa decisão pareceu dar prova.

\section{DAS PREMISSAS E FALÁCIAS DA NECESSIDADE DO TETO DE GASTOS PÚBLICOS}

Na mensagem ao texto da antiga PEC 241, observa-se que sua justificativa residia em um déficit público gerado supostamente pelo governo anterior, que teria gastado demais, gerando a necessidade de um ajuste fiscal, cuja opção foi tomada por meio do corte e limite dos gastos públicos como uma das medidas, ao lado das privatizações, para se atingir o chamado superávit primário. A atual EC 95/2016 é, por conseguinte, uma medida de ajuste fiscal que atende à lógica imposta pelo consenso neoliberal para as nações subdesenvolvidas ou em desenvolvimento, que pode ser sintetizada no tripé "superávit primário, meta inflacionária e câmbio flutuante", cujo resultado já se sabe: aprofundamento da desigualdade social e da recessão econômica e geração de lucros exclusivos e exorbitantes para muito poucos.

No Brasil, alcançar superávits primários elevados virou sinônimo de responsabilidade fiscal desde as crises econômicas do final dos anos 90 . Superávit primário nada mais é do que o dinheiro que o governo consegue economizar, ou seja, é aquilo que ele gasta (em despesas que não são financeiras) a menos do que arrecada, destinando o saldo remanescente para pagar os juros ou amortizações da dívida pública. Esse dado passou a ser um verdadeiro fetiche da política econômica neoliberal, pois ele traduz o risco de um governo dar calote na dívida ou não. Acontece que as justificativas brasileiras para a adoção do teto de gastos públicos no país estão permeadas de equívocos e até mesmo encobertas por um discurso oficial falacioso. A começar pela compreensão do déficit público, apresentado como um dado ruim, a significar necessariamente incompetência administrativa ou irresponsabilidade fiscal. Não é bem assim. País que investe, especialmente em infraestrutura, como o Brasil vinha fazendo nos últimos tempos, acumula déficit público, e esse dado pode significar também a adoção de uma política desenvolvimentista.

Também não é possível afirmar que o governo federal brasileiro, sob a direção anterior, gastou muito e foi irresponsável do ponto de vista fiscal, apresentando essa premissa como justificativa suficiente para a adoção do teto dos gastos públicos

redação: "A administração pública deve proceder ao desconto dos dias de paralisação decorrentes do exercício do direito de greve pelos servidores públicos, em virtude da suspensão do vínculo funcional que dela decorre, permitida a compensação em caso de acordo. O desconto será, contudo, incabível se ficar demonstrado que a greve foi provocada por conduta ilícita do Poder Público". 
federais. Houve uma desaceleração econômica já no final do primeiro mandato de Dilma Rousseff, que se fez acompanhar de uma grande queda nas receitas, esta última provocada também por equivocadas desonerações fiscais concedidas pelo governo Dilma ao setor produtivo e sobre a folha de salários, que não produziram, ao todo, um esperado aumento da capacidade produtiva e, consequentemente, aumento de receita.

Por outro lado, é preciso que se diga que se a sociedade brasileira deseja o Estado de Bem Estar Social projetado pela Constituição de 1988, isso requer investimento público. Não se alcança pela lógica do senso comum de se fazer muito com pouco ou de substituir o investimento público pelo investimento privado, como defendem as teorias econômicas clássicas. Isso não ocorre nem nos países paradigmáticos das economias de livre mercado, que gastam até mais do que o Brasil. ${ }^{11}$ Conforme projeção de alguns economistas de escol, como François Bourguignon, ex-Vice-presidente do Banco Mundial, o teto dos gastos públicos brasileiros, em médio prazo, deve reduzir as despesas do Estado em torno de 13\% do Produto Interno Bruto (PIB), o que é nível, segundo ele, de países africanos ${ }^{12}$. Países desenvolvidos gastam em torno de 3 (três) vezes mais para assegurar serviços públicos de qualidade, inclusive as economias de livre mercado. Nos países europeus, onde impera o Estado de Bem Estar Social, a média gira em torno de $49,9 \%$ do PIB. A França gasta 57\%, a Alemanha 44,1\% e a Finlândia, líder no ranking, 58,1\%, e é um dos maiores destaques em educação pública de qualidade. Nos Estados Unidos, gasta-se 38,8\%. Ou seja, até mesmo em uma economia onde o Estado tem um peso menor do que na Europa, há um modelo de compromisso mínimo com a população, nem que seja limitado por lá à educação, à defesa e outros serviços essenciais.

Em estudo encomendado pela Confederação Nacional da Indústria ao Banco Mundial, tendo por objeto analisar, comparativamente com outras nações, os obstáculos brasileiros à inovação e à competitividade, concluiu-se que um desses obstáculos seria o fato de o Brasil ter ficado "para trás" de seus competidores, especialmente da

\footnotetext{
11 Como ressalva Francisco de Oliveira: "o Estado mínimo da falsa utopia neoliberal não é mínimo na economia, como pregam os tolos: ele se faz mínimo é na política. Num movimento de pinças simultâneo, o Estado se faz máximo na economia e mínimo na política, e os dois lados projetam uma economia sem política, portanto sem disputa" (OLIVEIRA, Francisco de. O momento Lenin. In: OLIVEIRA, Francisco de; RIZEK, Cibele Saliba (Orgs.). A era da indeterminação. São Paulo: Boitempo, 2007. p. 257-287). No caso do Brasil, assim como de todas as economias subdesenvolvidas ou ainda em desenvolvimento, como já alertou Celso Furtado, uma presença forte do Estado se faz necessária porque em tais contextos os problemas decorrentes da industrialização tardia e da desigualdade social não encontram solução no mercado, que é guiado por critérios de racionalidade microeconômica. São problemas que requerem uma ação deliberada no plano político, pois as inovações tecnológicas que aqui surgem geram graves tensões sociais, pois resultam em uma progressiva sofisticação das formas de controle e abuso econômico exercidos pelos agentes que detêm o domínio da tecnologia, aprofundando as desigualdades (FURTADO, Celso. Raízes do subdesenvolvimento. Rio de Janeiro: Civilização Brasileira, 2003). 12 Disponível em: <http://br.rfi.fr/brasil/20161012-nivel-muito-baixo-de-gastos-publicos-ameaca-o-desenvolvimento.>.
} 
Ásia, na oferta de um serviço educacional de qualidade para todos os seus cidadãos. Ainda segundo o estudo, a economia global de hoje é a "economia do conhecimento", isto é, é um mundo em que trabalhadores inovadores e com boa escolaridade - e não matérias-primas e capacidade de produção industrial - são a chave da competitividade e do crescimento econômico. ${ }^{13}$ Logo, pouco investimento nos serviços públicos educacionais, como ocorre no Brasil, são grande entrave para o desenvolvimento. Quer dizer, segundo dados da OCDE, dentro dos gastos públicos totais do Brasil, a educação até que recebe uma atenção grande, superando a média da OCDE. Porém, quando se divide o gasto pelo total de alunos, o país fica em penúltimo lugar. $O$ alto grau de repetência e evasão acaba inflando o número de alunos e a baixa qualidade do ensino público também sobrecarrega o sistema. ${ }^{14}$

O próprio FMI, em julho de 2016, surpreendeu ao publicar um relatório ${ }^{15}$ pedindo que os países desenvolvidos, muitos deles submetidos a medidas severas de austeridade fiscal impostas pela União europeia após o colapso de 2008, acelerem os investimentos, especialmente em infraestrutura. Esse argumento, seguindo surpreendentemente a lógica keynesiana, é que, ao colocar dinheiro em grandes projetos (como o Brasil o fazia até então nas obras do Programa de Aceleração do Crescimento - PAC), esses países vão estimular a criação de empregos e renda, apoiando o crescimento econômico e acelerando a saída para a crise. Nesse mesmo relatório, inclusive, o FMI criticou a versão brasileira do teto para os gastos públicos.

Ainda segundo dados do FMI16, a proporção entre a dívida e o Produto Interno Bruto (PIB) caiu na Holanda, na Suécia e na Finlândia em um primeiro momento de suas experiências na adoção do teto de gastos públicos, mas não parou de subir depois da crise de 2008. Na Holanda, o indicador diminuiu de 71,7\%, em 1995, para 42,6\%, em 2007. Com a crise econômica, no entanto, o índice subiu até alcançar 68,3\%, em 2014. A dívida finlandesa equivalia a 42,7\% do PIB, em 2003, e foi reduzida gradualmente até $32,5 \%$, em 2008. Com a crise, cresceu sucessivamente até atingir 55,7\% em 2013. Logo, estabelecer cortes ou limites nos gastos públicos não é solução para as crises. A versão brasileira, portanto, também terá efeito de elevar a dívida, além de reduzir o PIB por aqui.

Esse cenário remete às lições extraídas da Estratégia do Desenvolvimento Econômico (1958), de Hirschman, cujo foco reside no questionamento acerca da validade das teorias propostas para o desenvolvimento econômico e na crítica de que as teorias de crescimento elaboradas até então seriam válidas para os países desenvolvidos, não

\footnotetext{
13 Disponivel em: <http://siteresources.worldbank.org/BRAZILINPOREXTN/Resources/3817166-1220382779545/ ConhecimentoelnovacaolivrocompletoPortugues.pdf $>$.

14 Disponível em: <https://www.oecd.org/edu/Brazil-EAG2014-Country-Note-portuguese.pdf>.

15 Disponível em: <http://www.bbc.com/portuguese/brasil-37558443>.

16 Disponível em: <http://www.imf.org/external/pubs/ft/weo/2015/01/weodata/index.aspx>.
} 
sendo compatíveis, por sua vez, com as peculiaridades dos países subdesenvolvidos: "a (teoria) econômica do desenvolvimento não se dedica extensivamente a economia do crescimento; os países subdesenvolvidos devem aprender a andar com suas próprias pernas, o que significa que devem trabalhar a sua própria abstração"17.18

Por sua vez, a teoria keynesiana, como se sabe, contestou a escola clássica, que não conseguia encontrar respostas para as crises do início do século XIX, sobretudo para a crise de 1929 nos EUA. Enquanto os economistas clássicos receitavam paciência para superar a crise que se colocava diante da economia americana, apontando que no longo prazo a economia se ajustaria de volta ao pleno emprego (algo semelhante ocorreu, no Brasil, com a propaganda do novo governo federal de Michel Temer em torno da aprovação da antiga PEC 241/55), Keynes já havia apontado em A Tract on Monetary Reform (1924) que "in the long run we are all dead".

Assim, ao divergir das teorias clássicas, na Teoria Geral do Emprego, do Juro e da Moeda,19 Keynes defendeu que as situações de desequilíbrio e de crise são inerentes às economias capitalistas, nas quais as situações de pleno emprego são raras e efêmeras. Por isso essas economias precisam ser equilibradas pela ação estatal, implicando que o Estado assuma funções de intervenção no domínio econômico, de combate ao desemprego, de promoção do pleno emprego, de redistribuição do rendimento e de segurança nacional. Pensando em outra alternativa para a superação de crises, Keynes defendeu, então, a intensificação dos investimentos, particularmente em infraestrutura. Segundo ele, quando os investimentos se intensificam, mais trabalhadores são empregados e a renda dos agentes econômicos aumenta, resultando no aumento tanto do consumo como da poupança. A partir de suas ideias, um maior nível de investimentos governamentais em infraestrutura e no sistema de serviços passou a ser compreendido como a melhor alternativa para superar as crises, pois tende a gerar externalidades positivas que estimulam o investimento do setor privado, principalmente em países

\footnotetext{
17 HIRSCHMAN, A. The strategy of economic development. New Haven: Yale University Press, 1958. p. 33.

18 Ou, ainda nesse mesmo sentido, a lúcida observação de Avelãs Nunes quanto ao rompimento do estruturalismo latino americano (CEPAL) com as teses clássicas e monetaristas: "mas foi contra as teses e as políticas económicas (sic) monetaristas que o estruturalismo latino-americano desenvolveu mais porfiados esforços, com vista a mostrar que a teoria neoclássica não poderia compreender e muito menos solucionar nenhum dos problemas económicos (sic) e sociais dos países subdesenvolvidos. Essencialmente por ignorar a estrutura sócio-económica (sic) própria de cada sociedade, por não enquadrar o subdesenvolvimento numa perspectiva histórica, como produto (ou subproduto) da própria história do desenvolvimento do capitalismo como sistema mundial (que integra o 'Terceiro Mundo'), por não considerar o quadro histórico-institucional em que o processo económico (sic) se desenvolve, e por prescindir, na sua análise, dos elementos sociais e políticos, considerados como externalidades, como elementos exógenos à economia" (NUNES, António José Avelãs. Neoliberalismo \& Direitos Humanos. Rio de Janeiro: Renovar, 2003. p. 103).
}

19 KEYNES, John Maynard. A teoria geral do emprego, do juro e da moeda. São Paulo: Nova Cultural Ltda, 1996. 
em desenvolvimento que se caracterizam pela falta de infraestrutura e/ou com baixa provisão de bens públicos. 20

Rocha e Teixeira, em Complementaridade versus Substituição entre Investimento Público e Privado na Economia Brasileira: 1965-90,21 analisaram o efeito do investimento público no Brasil, apresentando como um dos resultados o crescimento do PIB. Em Investimento em infraestrutura no Brasil: Fatos estilizados e relações de longo prazo, Ferreira faz também uma análise empírica acerca do efeito positivo que investimentos públicos realizados em infraestrutura exercem sobre o investimento do setor privado. Cruz e Teixeira, em The Impact of Public Investment on Private Investment in Brazil, 1947 - 1990,22 igualmente apontam que o investimento público pode ter efeito complementar sobre o investimento privado, principalmente quando são realizados em projetos de infraestrutura de grande porte, demonstrando que a atuação do Estado na economia é de grande relevância para o desenvolvimento do país. ${ }^{23}$

Com a Emenda Constitucional 95/2016, é possível concluir que o Brasil está fazendo o contrário do que deve ser feito em tempos de crise. Além do princípio keynesiano sobre os efeitos positivos dos investimentos públicos nos projetos de infraestrutura, o conceito de "multiplicador fiscal", de David Stuckler, também aponta para os efeitos igualmente positivos dos investimentos públicos em diferentes áreas, notadamente na saúde. Após estudar a política econômica de austeridade fiscal em 27 (vinte e sete) países, de 1995 a 2011, Stuckler, em A Economia desumana-porque mata a austeridade, critica o corte de gastos e aponta que os melhores índices multiplicadores, que geram retorno mesmo em tempos de crise, vêm de gastos com educação e saúde e os piores vêm com a defesa, os quais chegam a ser negativos em alguns países europeus. 24

\footnotetext{
20 Ressalve-se, como assinala Avelãs Nunes, que embora o keynesianismo tenha lançado as bases econômicas do welfare state, a teoria nada tinha de revolucionária, apresentando-se antes como solução para a sobrevivência do próprio sistema capitalista, diante da constatação de suas inarredáveis crises cíclicas. Por isso a frustração gerada com as teses keynesianas quanto a um resultado mais impactante e transformador do Estado providência acerca do resultado das políticas de redistribuição de rendimentos. Mesmo assim, os neo-keynesianos continuam defendendo o princípio da responsabilidade social coletiva, decorrente do welfare state, e o mesmo continua a inspirar esse modelo, principalmente na Europa (NUNES, António José Avelãs. Neoliberalismo \& Direitos Humanos. Rio de Janeiro: Renovar, 2003. p. 32-35).

21 ROCHA, Carlos Henrique; TEIXEIRA, Joanílio Rodopolho. Complementaridade versus substituição entre investimento público e privado na economia brasileira: 1965-90. Revista Brasileira de Economia, Rio de Janeiro, v. 50, n. 3, p. 378-384, jul./set. 1996.

22 CRUZ, Bruno de Oliveira; TEIXEIRA, Joanílio R. Cepal Review, [s.l.] v. 67, p. 75-84, apr. 1999.

23 Sobre o assunto, recomenda-se a revisão de literatura ora citada, os estudos empíricos e a análise histórica do investimento público brasileiro, retratadas em CONTE FILHO, Carlos Gilbert. Uma análise empírica acerca do efeito do investimento público sobre o investimento privado no Brasil: 1971-2008. Rio de Janeiro, 2013. 198 f. Tese (Doutorado). Programa de Pós Graduação em Economia. Universidade Federal do Rio de Janeiro.
}

24 STUCKLER, David; BASU, Sanjay. A economia desumana - por que mata a austeridade. Portugal: Bizancio, 2014. 
Desse modo, falar em recuperação da economia ou em crescimento econômico deve passar ao largo da compreensão de um ajuste fiscal baseado unicamente em obtenção de superávit primário por meio do corte de gastos públicos. A opção não deve ser apenas ideológica, portanto, a limitar-se à contraposição das ideias a respeito do tamanho do Estado. Até mesmo porque nessa seara o senso comum parece infelizmente prevalecer, resultando em grandes distorções de entendimento que atrasam o desenvolvimento econômico brasileiro e impedem uma análise frutífera e racional das complexidades brasileiras, em se admitindo que a maior parte da sociedade civil ainda deseja o projeto constituinte de 1988, que direciona a implantação do Estado de Bem Estar Social, acreditando, paradoxalmente, que isso pode ocorrer com a adoção de receitas do ideário neoliberal.

Faz-se a ressalva acima porque, ao que parece, o cidadão médio brasileiro não tem a exata compreensão de que para usufruir de serviços públicos de qualidade é necessário o investimento público. Quanto mais um país gasta para assegurar serviços públicos, menos os cidadãos terão que pagá-los por meio da iniciativa privada. E aqui reside justamente o "Paradoxo de Rousseau" dos brasileiros, retratado na obra homônima de Wanderley Guilherme dos Santos, 25 que critica o comportamento do cidadão médio brasileiro em desejar usufruir do modelo europeu de serviços públicos, pagando o mínimo de tributação. Esse paradoxo, bastante atual, foi visto inclusive nas manifestações de rua de 2016, de tonalidades verde-amarelo, a sustentar cartazes com escritos de que sonegação fiscal seria legítima defesa no Brasil. Muitos dos cidadãos que empunhavam tais cartazes eram estudantes e professores de universidades públicas ou servidores públicos.

O que parece certo, ao contrário, é que o desenvolvimento econômico não pode depender apenas dos investimentos privados, notadamente porque há setores, como infraestrutura de transportes e energia, onde devido ao grande vulto e risco dos investimentos a atuação estatal se faz imprescindível. Agregando também o conceito dos "multiplicadores fiscais", de David Stuckler, conclui-se que a atuação do Estado é igualmente imprescindível em diferentes áreas, notadamente saúde e educação, onde, no caso do Estado brasileiro, o investimento tem sido muito tímido, diferentemente do discurso oficial de defesa do teto dos gastos públicos. O Brasil gasta muito, mas não com os direitos sociais (ressalvado o aparente investimento considerável em educação, segundo a OCDE, que se dilui levando em consideração o gasto por número de alunos...).

Exemplifique-se com o problema da dívida pública externa brasileira, cujo pagamento de juros e amortizações resulta em quase 50\% da arrecadação do Tesouro

25 SANTOS, Wanderley Guilherme dos. O paradoxo de Rousseau: uma interpretação democrática da vontade geral. Rio de Janeiro: Rocco, 2007. 
Nacional ano a ano26, levando a sociedade brasileira a remunerar credores e investidores estrangeiros, cuja identidade não é conhecida, e que detêm a maior parcela do estoque da dívida (mais de 62\%). O país tem emitido títulos da dívida pública para pagar juros, endividando-se sucessivamente, inclusive em operação vedada pela lei, pois os juros são considerados despesas correntes pela Lei federal n. ${ }^{\circ} 4.320 / 64$, e a Constituição Federal, no art. 167, veda a emissão de títulos da dívida para pagamento das despesas correntes. Enquanto metade do orçamento federal é consumido com o pagamento de juros e amortizações da dívida, destina-se 0,27\% para ciência e tecnologia, 0,01\% para saneamento básico, 0,04\% para a cultura, 0,56\% para os transportes, 0,34\% para segurança pública, 0,03 \% para desporto e lazer, 0,87\% para agricultura, 0,05\% para urbanismo, 4,41\% para a saúde e 3,91\% para a educação.

Em número de servidores públicos, segundo dados da OCDE27, o Brasil segue a média da América Latina, que é inferior à média de países desenvolvidos. A cada 100 (cem) trabalhadores brasileiros, 12 (doze) são servidores públicos, enquanto nos países mais desenvolvidos, o percentual costuma ser no mínimo o dobro, sendo a média de 21 (vinte e um) servidores para cada 100 (cem) trabalhadores. Em nações como Noruega e Dinamarca, mais de 1/3 da população economicamente ativa está empregada no serviço público. Logo, não há excesso de servidores públicos no Brasil. Obviamente, do ponto de vista numérico, o quantitativo pode ser expressivo, mas se deve ter em mente que se trata de um país com uma grande população, a quinta maior no mundo. Então não se pode analisar os números de forma descontextualizada. O que preocupa no Brasil não é o número de servidores, mas talvez a desigualdade na sua distribuição em cada área e a política diferenciada de remuneração28. Há uma desproporção no número de servidores entre áreas urbanas e rurais, entre as capitais e o resto do país e entre os serviços do centro e da periferia. Há também políticas de remuneração de elites no funcionalismo público (fiscalização, Magistratura e Ministério Público, por exemplo).

Especificamente no tocante à saúde, aquele mesmo estudo do início de outubro de 2016, do IPEA, já citado, aponta que o gasto com saúde no Brasil é de 4 (quatro) a 7 (sete) vezes menor do que o de países que têm um efetivo sistema universal de saúde, como o Reino Unido e a França, e é inferior ao de países da América do Sul, nos quais o sistema de saúde não é sequer universal, como na Argentina e no Chile. Nesse contexto, é conveniente registrar que a União Europeia proíbe os países membros de regular o seguro privado (o PHI) quando houver o sistema nacional de saúde (SNS), com o argumento de defender o sistema estatutário, que pode ser ameaçado pela concorrência de um sistema privado.

\footnotetext{
26 Disponível em: <http://www.auditoriacidada.org.br/blog/2016/11/09/explicacao-sobre-o-grafico-do-orcamento-elaborado-pela-auditoria-cdada-da-divida $>$.

27 Disponível em: <https://www.oecd.org/eco/surveys/Brasil-2015-resumo.pdf>.

28 Disponível em: <http://www.ipea.gov.br/portal/index.php?option=com_content\&view=article\&id=18638>.
} 
No Brasil, o objetivo da EC 95/2016 é fazer justamente o contrário. Reforçar, com o limite dos investimentos públicos, o sistema de saúde privado, coroando o princípio friedmaniano da liberdade de escolha, fundante da Escola conservadora de Chicago.29 Por isso é que, seguindo a mesma lógica da União europeia, Carlos Octávio Ocké-Reis, na obra SUS: o desafio de ser único, aponta como principais obstáculos à efetividade e à universalidade do SUS brasileiro a concorrência dos planos privados de saúde e os subsídios generosos que eles recebem do próprio Estado, e não propriamente motivos ligados à gestão do sistema. 30 Essa mesma análise também pode ser encontrada em $O$ preço da desigualdade, de Joseph Stiglitz, ${ }^{31}$ que projeta o colapso do nível de vida da sociedade norte-americana, desassistida de um sistema público e universal de saúde, em um futuro muito próximo, que já começou.

Ou seja, de tudo o que se disse acima, é possível extrair que a EC 95/2016 pretende alcançar um equilíbrio fiscal pelo lado do corte do gasto, e não pelo investimento, o que é um grande equívoco. Outra opção também poderia ter sido por reformas no sistema de arrecadação, que igualmente são capazes de promover um ajuste fiscal. A EC deixa imune a leveza da tributação brasileira sobre as grandes propriedades e as rendas do capital, que fazem com que a conta da carga tributária seja cada vez mais centralizada nos mais pobres e nos rendimentos do trabalho e no consumo. Por isso que foi dito inicialmente que a medida é uma clara opção por privilegiar certos setores, nacionais e estrangeiros, tendo em vista que há outras opções ao teto de gastos, que são eficazes, algo que ele (o teto) não é.

A receita para a crise brasileira não é, portanto, o teto de gastos públicos, que não vai aplacar a crise, mas sim sabotar completamente a Constituição, e a curto e médio prazo, agravar a própria crise. Uma redução gradual dos juros em conjunto com o fim da isenção dos dividendos (o Brasil, ao lado da Estônia, é um dos únicos países do mundo que, a partir do governo $\mathrm{FHC}$, passou a não tributar a distribuição dos lucros), a reforma da tabela progressiva do Imposto de renda, a criação do Imposto sobre Grandes Fortunas e de um Imposto sobre o valor Agregado (IVA) para substituir PIS, Cofins, IPI, ICMS, ISS e contribuição previdenciária sobre a receita das empresas, seriam medidas capazes de gerar superávit ao mesmo tempo que se corrigiriam falhas graves na economia brasileira. Essa é uma das conclusões de estudo publicado em dezembro de 2016 pelo Centro Internacional de Políticas para o Crescimento Inclusivo (IPC-IG), vinculado ao Programa das Nações Unidas para o Desenvolvimento (PNUD). O texto faz uma análise crítica da tributação da renda e do lucro no Brasil, mostrando como medidas tomadas nas décadas de 1980 e 1990, restringiram o papel distributivo do Imposto

\footnotetext{
29 FRIEDMAN, Milton; FRIEDMAN, Rose. Liberdade para escolher. 2. ed. Trad. Ana Maria Sampaio et all. Portugal: Publicações Europa-América, 1980.

30 OCKÉ-REIS, Carlos Octávio. SUS: o desafio de ser único. Rio de Janeiro: Fiocruz, 2012.

31 STIGLITZ, Joseph. $O$ preço da desigualdade. Trad. Dinis Pires. Lisboa: Bertrand, 2014.
} 
de Renda, resultando em alta concentração de renda no topo da distribuição, baixa progressividade e violação do princípio da equidade, sendo a principal razão dessas distorções a isenção dos dividendos 32 .

A instituição do IGF também geraria um incremento considerável de receita. Nesse sentido, uma nota técnica do IPEA de mais de 50 (cinquenta) páginas, contrariando as críticas relativas a uma baixa arrecadação, aponta que as causas para essa subestimação residem em algumas experiências estrangeiras onde foram estabelecidos um elevado limite de isenção, baixas alíquotas, a não incidência sobre pessoas jurídicas, a transferência da riqueza financeira para paraísos fiscais e a subavaliação dos imóveis. Por outro lado, em países em que o imposto existe, como França, Argentina e Uruguai, com respectivos $1,6 \%, 1,5 \%$ e $6,3 \%$ das receitas do governo representadas pela arrecadação do imposto em 2009, ele apresenta tendência de crescimento da arrecadação e do número de contribuintes. Também revertendo a tendência da década de 1990, países como Islândia e Espanha reinstituíram o imposto recentemente como resposta à crise financeira e fiscal iniciada em 2008. O estudo mostra, assim, que a tendência internacional para uma maior eficiência e arrecadação do IGF seria o menor número de alíquotas, um limite de isenção mais baixo, a abrangência de pessoas jurídicas, a tributação especial para não residentes e a presença de normas antievasivas severas. Por outro lado, o estudo mostra também, empiricamente, que a concentração da riqueza é superior à da renda, e que em uma amostra significativa de países, 2,5\% das famílias mais ricas do mundo, isto é, inseridas no grupo de $1 \%$ com as maiores fortunas do mundo, eram brasileiras, e que isso demostra o potencial arrecadatório e distributivo que a instituição do imposto, se bem aplicada, poderia gerar no País33.

Essa receita para a crise, na verdade, é universal, embora encontre sofisticadas e bem elaboradas formulações na inteligência brasileira. O próprio Stiglitz, no Capítulo 10 de o Preço da Desigualdade,34 afirma que o caminho para o combate à crise e à desigualdade social passa por várias medidas, entre elas: 1) conter os excessos do topo, ou seja, conter o setor financeiro; 2) endurecer as leis de concorrência; 3) acabar com a assistência pública às grandes empresas; 3 ) criar um sistema tributário mais progressivo sobre os rendimentos individuais e o lucro das sociedades; 4) criar um sistema de imposto sobre heranças mais eficaz e mais eficazmente aplicado, para prevenir a criação de novas oligarquias; 5) adotar sistemas universais de saúde; 6) promover uma agenda de crescimento baseada no investimento público.

\footnotetext{
32 Disponível em: <http://www.ipc-undp.org/pub/port/WP136PT_Tributacao_e_distribuicao_da_renda_no_ Brasil_novas_evidencias_a_partir_das_declaracoes_tributarias_das_pessoas.pdf $>$.

33 Disponível em: <http://www.ipea.gov.br/agencia/images/stories/PDFs/nota_tecnica/111230_notatecnicadinte7.pdf>.

34 STIGLITZ, Joseph. 0 preço da desigualdade. Trad. Dinis Pires. Lisboa: Bertrand, 2014.
} 
Igual solução também é apresentada por Thomas Piketty, em O Capital no século XXI,35 onde, mais especificamente na Quarta Parte, ele aponta para a necessidade de se regular o capital para combater as crises e reestabelecer o papel do Estado na produção e distribuição das riquezas e na construção de um Estado social adaptado ao século XXI. Mariana Mazuccatto também demonstra que o Estado, como agente empreendedor, possui papel fundamental neste século XXI. Sua obra chama-se O Estado Empreendendor: desmascarando o mito setor público vs. setor privado,36 onde a pesquisadora demonstra a fundamentalidade da participação do governo do Estado americano em grandes avanços tecnológicos dos últimos tempos, como os produtos da Apple, Iphone, Ipad e Ipod, que não teriam sido possíveis sem a participação das agências de pesquisas do governo americano.

Logo, o problema brasileiro, como também o de outros países, não é de excessos do intervencionismo estatal ou de excesso de gastos com os direitos sociais. O Brasil ostenta, contudo, uma particularidade: a mentalidade tacanha de nossas elites econômicas, que não se importam em desconstruir um projeto de país soberano e mais justo socialmente, para manter seus privilégios. Ou, como já identificaram os economistas do desenvolvimento e estruturalistas da Comissão Econômica para a América Latina e o Caribe das Nações Unidas (CEPAL), entre eles, Raul Prebisch, Celso Furtado e Maria da Conceição Tavares, cujas ideias dominaram o pensamento econômico nas décadas de 1960 e 1970 (mostrando-se acertadas e atuais aos tempos presentes), é uma ilusão em se pensar na existência de uma burguesia nacional na América latina, uma vez que as elites locais são intrinsecamente dependentes e incapazes de liderar uma revolução capitalista nacional clássica, uma vez que são colonizadas culturalmente pelo que Celso furtado denunciou como o "mito do desenvolvimento"37. A EC 95/2016 representa, afinal, a reação dos setores políticos e econômicos conservadores da sociedade brasileira, que nunca aceitaram uma constituição que pretendeu ser dirigente e que pretendeu implantar um Estado Social no Brasil, determinando a função social da propriedade a intervenção do Estado nos domínios econômico e social. Aliás, que nunca aceitaram nem mesmo o protagonismo do País na exploração estratégica dos seus recursos naturais, como têm demonstrado as sucessivas aprovações ao Projeto de Lei n. ${ }^{\circ}$ 4567/16, de autoria do José Serra, atual Ministro das Relações Exteriores.

35 PIKETTY, Thomas. O Capital no século XXI. Trad. Monica Baumgarten de Bolle. Rio de Janeiro: Intrínseca, 2014.

36 MAZZUCATO, Mariana. O Estado Empreendendor: desmascarando o mito setor público vs. setor privado. São Paulo: Portfolio-Penguim, 2014.

37 Essa construção de Celso Furtado traduz a ideia equivocada de que o desenvolvimento dos países subdesenvolvidos exigiria que estes adotassem as estruturas produtivas dos países capitalistas industrializados, com o objetivo de proporcionar aos respectivos povos os padrões de consumo e as formas de vida dos países desenvolvidos. Tal mito seria, assim, um dos pilares da doutrina que serve de cobertura à dominação dos povos dos países periféricos dentro da nova estrutura do capitalismo (FURTADO, Celso. O mito do desenvolvimento econômico. 3. ed. Rio de Janeiro: Paz e Terra, 1974). 
Por fim, e para além da disputa da narrativa entre golpe ou impeachment sobre o afastamento presidencial de Dilma Rousseff, é necessário insistir que esses postulados (do Estado Social) são normas constitucionais, e não inovações ou especificidades dos conteúdos programáticos dos partidos da esquerda brasileira.

\section{CONSIDERAÇÕES FINAIS}

A EC 95/2016, ao constituir uma opção equivocada por alcançar superávit primário por meio do limite de gastos, aprofundando a crise econômica para satisfazer setores ligados ao capitalismo rentista, parece mais uma medida que pretende devolver o país ao seu habitual Estado de exceção econômico, imposto pelo mainstream, aliás, a toda a América latina. Isto é, trata-se de um obstáculo neocolonialista ao desenvolvimento soberano de economias periféricas, que vivenciaram nos últimos tempos governos com tendências populares e mais democratizantes, com o objetivo de domesticá-las na tradicional relação econômica de dependência com as economias do capitalismo central38 39 .

38 A teoria da dependência, em uma de suas vertentes, caracterizava o pensamento econômico convencional como um instrumento que promovia os interesses dos países mais desenvolvidos (dos Estados Unidos e do Reino Unido em particular), que não enxergavam favoravelmente a industrialização em curso na América Latina nas décadas de 1950 a 1970. Desse modo, os pensadores dessa vertente atribuíram a responsabilidade pelo subdesenvolvimento da região não apenas à colonização mercantilista da América Latina por meio dos latifúndios, mas também ao interesse ativo do centro imperial em manter os países em desenvolvimento como exportadores de bens primários. Desse modo, subscreviam uma versão da teoria imperialista do subdesenvolvimento - a teoria que explica o subdesenvolvimento na América Latina, durante o século XIX, pela subordinação informal das suas sociedades mercantil-capitalistas aos países industriais e imperiais da Europa e da América do Norte (BRESSER-PEREIRA, Luiz Carlos. As três interpretações da dependência. Perspectivas, São Paulo, v. 38, p. 17-48, jul./dez. 2010). Nesse sentido, e ainda desmistificando a ideia do subdesenvolvimento como "fase" ou "etapa" do desenvolvimento, dizia Celso Furtado: "consideraremos o subdesenvolvimento como uma criação do desenvolvimento, isto é, como consequência do impacto, em grande número de sociedades, de processos técnicos e de formas de divisão do trabalho irradiados do pequeno número de sociedades que se haviam inserido na revolução industrial em sua fase inicial, ou seja, até fins do século XIX. As relações que se estabelecem entre esses dois tipos de sociedades envolvem formas de dependência que tendem a autoperpetuar-se. Essa dependência apoiou-se, inicialmente, num sistema de divisão internacional do trabalho que reservava para os centros dominantes as atividades produtivas em que se concentrava o progresso tecnológico. Em fase subsequente, a dependência resultou do controle exercido por grupos das economias dominantes sobre as atividades que, nas economias dependentes, mais assimilavam novas técnicas" (FURTADO, Celso. Raízes do subdesenvolvimento. Rio de Janeiro: Civilização Brasileira, 2003. p. 88).

39 Utilizamos os termos centro e periferia do capitalismo também por se tratar de conceitos fundamentais na teoria da CEPAL. Como bem sintetiza Ricardo Bielschowsky, que integra a Comissão no Chile, a dicotomia centro-periferia "é empregada ara descrever o processo de difusão do progresso técnico na economia mundial e para explicar a distribuição de seus ganhos. De acordo com este conceito, a divisão internacional do trabalho provocou, desde os primeiros estágios do capitalismo industrial, efeitos diferenciados nas economias das duas regiões, fazendo com que ambas se distanciassem crescentemente em termos de estágio de desenvolvimento. A tese parte da idéia (sic) de que o progresso técnico se desenvolveu de forma desigual nos dois pólos. Foi mais rápido no centro, em seus setores industriais, e ainda mais importante, elevou simultaneamente a produtividade de todos os setores das economias centrais, provendo um nível técnico mais ou menos homogêneo em toda a extensão dos seus sistemas produtivos. Na periferia, que teve a função de suprir o centro com alimentos e matérias-primas a baixo preço, o progresso técnico só foi introduzido nos setores de exportação, que eram verdadeiras ilhas de alta produtividade, em forte contraste com o atraso do restante do sistema produtivo 
Nisso reside o Estado de exceção econômico permanente a que está submetida a América Latina, tema desenvolvido por Gilberto Bercovici, entre outras, na obra Constituição e estado de exceção permanente: atualidade de Weimar. ${ }^{40}$ Segundo Bercovici, a normalidade caracteriza o capitalismo central, enquanto a periferia vive em um estado de exceção econômico permanente, contrapondo-se à normalidade do centro. Nos Estados periféricos há o convívio do decisionismo de emergência para salvar os mercados com o funcionamento dos poderes constitucionais, bem como a subordinação do Estado ao mercado, com a adaptação do direito interno às necessidades do capital financeiro, exigindo cada vez mais flexibilidade para reduzir as possibilidades de interferência da soberania popular. A razão de mercado passa a ser a nova razão de Estado.

Na normalidade do centro, as leis de emergência interferem nas liberdades políticas e econômicas, limitando os direitos individuais tendo em vista o bem-estar coletivo. Na periferia ocorre o contrário: a utilização dos poderes de emergência caracteriza-se por limitar os direitos da população em geral para garantir a propriedade privada e a acumulação capitalista. Desse modo, a América Latina, além da crise econômica interna, é vítima de fatores externos de instabilidade econômica. Os poderes discricionários do Executivo são mais plausíveis, especialmente, para os países dependentes de decisões do Fundo Monetário Internacional e da Organização Mundial do Comércio, que constituem poderes de exceção sem qualquer contrapartida. As pressões internas e externas sobre as burguesias locais (incapazes de uma revolução capitalista nacional clássica, como já concluíram os estudiosos da (EPAL) para a execução de políticas neoliberais fazem perpetuar, continuamente, a dependência dos poderes econômicos de emergência.

A análise de Bercovici também se assenta, no fundo, na Teologia Política de Carl Schmitt, que desloca o conceito de soberania, fundamento da autoridade política que reside na sua legitimidade democrática, para o conceito de "soberano é quem decide sobre o estado de exceção".41 Sua tese concebe uma visão de polaridade amigo-inimigo, que conduz a uma guerra permanente e necessária dentro do sistema para criar e manter a paz interna, demandando a união de todos os cidadãos para lutar contra o inimigo comum, sendo que esse inimigo é político e assim o é porque é definido por um ato do soberano. E assim o inimigo passa a ocupar um conceito fundante da política.

Segundo Schmitt, o estado de exceção se justifica pela situação de ameaça à unidade política, o que, em uma economia periférica, como a brasileira, se traduz como ameaça à ordem capitalista, à soberania dos mercados. Se o mercado é o soberano, o

(BIELSCHOWSKY, Ricardo. Pensamento Econômico brasileiro: o ciclo ideológico do desenvolvimentismo. 4. ed. Rio de Janeiro: Contraponto, 2000. p. 16).

40 BERCOVICl, Gilberto. Constituição e Estado de exceção permanente: atualidade de Weimar. Rio de Janeiro: Azougue, 2004.

41 SCHMITT, Carl. Teologia Política. Trad. Elisete Antoniuk. Belo Horizonte: Del Rey, 2006. 
Estado, naturalmente propenso à corrupção, é o inimigo, como "o conto de fadas para adultos" quer fazer crer, reservando a virtude ao mercado. $42 \mathrm{E}$ de fato, desde o resultado das eleições presidenciais de 2013, observou-se surgir com força no debate político essa polarização mercado x Estado, fazendo ressurgir a tese schmittiana do amigo-inimigo, que também constitui o pano de fundo da EC 95/2016.

O novo regime fiscal, inaugurado pela EC 95/2016, e apresentado como solução (na nossa opinião desatinada) para a recente crise econômica brasileira, também remete ao chamado "capitalismo do desastre", retratado em A doutrina do choque, de Naomi Klein. ${ }^{43}$ Há semelhanças que autorizam traçar um paralelo entre o estado de sítio fiscal, imposto agora ao Brasil por obra da Emenda 95/2016, e as medidas impopulares impostas ciclicamente por forças do capitalismo central nas situações de crise econômica. Klein demonstra que as tais forças aproveitam-se historicamente de períodos de crises econômicas, guerras, desastres naturais, ataques terroristas e epidemias, para assaltar os interesses públicos nacionais e locais e levar a cabo todo tipo de reformas a favor do livre mercado, e que longe de ser o caminho para a liberdade, as medidas de choque econômico aprofundam as crises, as desigualdades e a violência. No caso brasileiro, a crise econômica e o afastamento presidiencial de Dilma Rousseff, ao que parece, foram as oportunidades encontradas para mais uma medida de "choque" ou de "desastre".

$O$ teto de gastos públicos do governo federal brasileiro, implementado pela EC $95 / 2016$, é, portanto, uma ofensiva conservadora de retirada de direitos sociais, tendo como alvo prioritário o projeto constituinte de 1988, que exige a intervenção do Estado para a redução das severas desigualdades sociais e econômicas, necessária para uma economia verdadeiramente soberana. $\mathrm{O}$ ataque também é à concepção neo-desenvolvimentista desse mesmo projeto constituinte, que reserva ao investimento público papel essencial ao estímulo do investimento privado e do crescimento do setor produtivo nacional, com o intuito de reduzir a dependência do país às potências estrangeiras hegemônicas.

Dessa forma, independentemente das opções político-partidárias (e para além delas), é preciso que a sociedade civil brasileira tome consciência de que o plano econômico traduzido pela EC 95/2016 afronta o projeto político e constituinte de 1988, referendado nas últimas eleições presidenciais de 2014. A EC 95/2016 não foi, afinal, o projeto político e constitucional vencedor nestas últimas eleições. Um vice-presidente alçado à condição de presidente, por um impeachment ou um golpe, qualquer que seja a narrativa, não poderia impor agora um novo regime fiscal que represente, como a EC 95/2016 o faz, um projeto político constituinte diametralmente oposto ao de 1988 ,

42 SOUZA, Jessé. A tolice da inteligência brasileira: ou como o país se deixa manipular pela elite. São Paulo: LeYa, 2015. p. 221-252.

43 KLEIN, Naomi. A doutrina do choque: a ascensão do capitalismo de desastre. Trad. Vania Cury. Rio de Janeiro: Nova Fronteira, 2008. 
não vencedor nas urnas. Por conseguinte, além de suas inconstitucionalidades, infelizmente afastadas pelo Supremo Tribunal Federal no MS 34.448-MC/DF, a EC 95/2016 padece de legitimidade democrática, sendo ainda um projeto desastroso de solução de uma crise econômica, e aparentemente motivado para sabotar os avanços do país na implementação de um Estado de Bem Estar Social e de uma economia mais soberana e independente, outrora capaz de influenciar a consolidação de um projeto de autonomia de toda a América latina e de seus povos.

Ao Supremo Tribunal Federal, fica aqui a lembrança, também de outrora, do legado jurisprudencial da ADPF 45 e do até então firme posicionamento do Ministro Celso de Mello nesse julgamento. A ordem constitucional brasileira e, portanto, a sua Corte guardiã, não deveriam admitir ou chancelar a tese da falta de recursos orçamentários como argumento capaz de legitimar a pretensão dos grupos dominantes de pressão em desvencilhar o Estado de suas obrigações constitucionais para com o pacto civilizatório e emancipador da Constituição de 1988. Afinal, os problemas do Brasil, conforme apontaram os estudos técnicos citados ao longo deste trabalho, não são de escassez de recursos ou de irresponsabilidade fiscal, mas da permanência de uma organização sócio-econômica garantida pelo poder político de uma forma de Estado (neoliberal) que existe para a defesa das classes dominantes e não para a defesa de todos.

\section{REFERÊNCIAS}

BERCOVICI, Gilberto. Constituição e Estado de exceção permanente: atualidade de Weimar. Rio de Janeiro: Azougue, 2004.

BIELSCHOWSKY, Ricardo. Pensamento Econômico brasileiro: o ciclo ideológico do desenvolvimentismo. 4. ed. Rio de Janeiro: Contraponto, 2000.

BRESSER-PEREIRA, Luiz Carlos. As três interpretações da dependência. Perspectivas, São Paulo, v. 38, p. 17-48, jul./dez. 2010.

CONTE FILHO, Carlos Gilbert. Uma análise empírica acerca do efeito do investimento público sobre o investimento privado no Brasil: 1971-2008. Rio de Janeiro, 2013. 198 f. Tese (Doutorado). Programa de Pós-Graduação em Economia - Universidade Federal do Rio de Janeiro.

CRUZ, Bruno de Oliveira; TEIXEIRA, Joanílio R. Cepal Review, [s.I.] v. 67, p. 75-84, apr. 1999. FRIEDMAN, Milton; FRIEDMAN, Rose. Liberdade para escolher. 2. ed. Trad. Ana Maria Sampaio et all. Portugal: Publicações Europa-América, 1980.

FURTADO, Celso. O mito do desenvolvimento econômico. 3. ed. Rio de Janeiro: Paz e Terra, 1974. FURTADO, Celso. Raízes do subdesenvolvimento. Rio de Janeiro: Civilização Brasileira, 2003. HIRSCHMAN, A. The strategy of economic development. New Haven:Yale University Press, 1958. 
KERSTENETZKY, Celia Lessa. O Estado do Bem Estar Social na Idade da Razão: a reinvenção do Estado social no mundo contemporâneo. Rio de Janeiro: Elsevier, 2012.

KEYNES, John Maynard. A teoria geral do emprego, do juro e da moeda. São Paulo: Nova Cultural Ltda, 1996.

KEYNES, John Maynard. A tract on monetary reform. London: Macmillam and Co., 1924.

KLEIN, Naomi. A doutrina do choque: a ascensão do capitalismo de desastre. Trad. Vania Cury. Rio de Janeiro: Nova Fronteira, 2008.

MAZZUCATO, Mariana. O Estado Empreendendor: desmascarando o mito setor público vs. setor privado. São Paulo: Portfolio-Penguim, 2014.

NUNES, António José Avelãs. Neoliberalismo \& Direitos Humanos. Rio de Janeiro: Renovar, 2003. OCKÉ-REIS, Carlos Octávio. SUS: o desafio de ser único. Rio de Janeiro: Fiocruz, 2012.

OLIVEIRA, Francisco de. O momento Lenin. In: OLIVEIRA, Francisco de; RIZEK, Cibele Saliba (Orgs.). A era da indeterminação. São Paulo: Boitempo, 2007.

PIKETTY, Thomas. O Capital no século XXI. Trad. Monica Baumgarten de Bolle. Rio de Janeiro: Intrínseca, 2014.

ROCHA, Carlos Henrique; TEIXEIRA, Joanílio Rodopolho. Complementaridade versus substituição entre investimento público e privado na economia brasileira: 1965-90. Revista Brasileira de Economia, Rio de Janeiro, v. 50, n. 3, p. 378-384, jul./set. 1996.

SANTOS, Wanderley Guilherme dos. 0 paradoxo de Rousseau: uma interpretação democrática da vontade geral. Rio de Janeiro: Rocco, 2007.

SCHIER, Adriana da Costa Ricardo. Serviço Público: garantia fundamental e cláusula de proibição de retrocesso social. Curitiba: Íthala, 2016

SCHMITT, Carl. Teologia Política. Trad. Elisete Antoniuk. Belo Horizonte: Del Rey, 2006.

SINGER, André. Os sentidos do lulismo: Reforma gradual e pacto conservador. São Paulo: Companhia das Letras, 2012.

SOUZA, Jessé. A tolice da inteligência brasileira: ou como o país se deixa manipular pela elite. São Paulo: LeYa, 2015.

STIGLITZ, Joseph. O preço da desigualdade. Trad. Dinis Pires. Lisboa: Bertrand, 2014.

STUCKLER, David; BASU, Sanjay. A economia desumana - por que mata a austeridade. Portugal: Bizancio, 2014.

TAVARES, Maria da Conceição. A Retomada da hegemonia norte-americana. In FIORI, José Luís (Org.). Poder e dinheiro: uma economia política da globalização. Petrópolis: Vozes, 1997. 